\section{Reaction time to change in visual orientation*}

\author{
ALBERTA S. GILINSKY† \\ University of Bridgeport, Bridgeport, Connecticut 06602 \\ and \\ H. HARVEY COHEN \\ University of North Carolina, Durham, North Carolina 27707
}

The aftereffects of viewing diagonal lines for 50,500 , and 1,000 msec were measured by the speed and accuracy of identification of a variably tilted test grating. Significant RT and tilt aftereffects were found as functions of the duration of orientation-specific adaptation and the angle of separation between inspection and test lines. The results throw light on anchoring effects of the main visual coordinates and support a structural interpretation of orientational selectivity in human vision.

Traditional psychophysical studies of feature detectors in human vision rely on threshold sensitivity measures such as masking (Weisstein, 1969) and lack direct comparability with electrophysiological research using suprathreshold stimuli on experimental animals. The present study attempts to link the threshold studies of orientational selectivity in man with measures of the speed and accuracy of human visual response to large easily discriminable line patterns. Two methods, reaction time (RT) and absolute judgment, were used under conditions comparable to those in experiments on visual masking by orientational adaptation.

This experiment applied both methods simultaneously in order to obtain converging evidence on the speed and accuracy of perceiving variably oriented test lines following different periods of exposure to inspection lines fixed at one particular orientation. These variables, the aftereffects produced by viewing tilted lines for various periods of time on the discrimination of orientation, have aroused recent theoretical interest (Coltheart, 1971; Over, 1971).

Gilinsky (1967, 1968) found that lengthening the duration of exposure from 250 to 5,000 msec in which Os viewed horizontal, vertical, or diagonal line gratings greatly increased the masking effect on test gratings with identical orientations. The major results of this experiment were confirmed by an attempted nonreplication (Woll, Eriksen, \& Hake, 1970) that used as adapting durations, $55,1,000$, and 3,200 msec and vertical and horizontal adapting patterns. Although these investigators were at pains to discredit the original study,

\footnotetext{
*This research was supported in part by NSF Grant GB-6067. The authors wish to express their gratitude to Irwin Pollack for helpful criticism of an earlier draft and many constructive suggestions.

tRequests for reprints should be sent to Alberta Gilinsky. Physiological Laboratory, Cambridge CB2 3EG, England.
}

they found clear evidence for significant masking effects as a function of increasing duration of exposure to the same vs the opposite adapting orientation.

Blakemore and Campbell (1969) also found marked adaptation effects on the contrast threshold and on the human occipital evoked potential as a function of adaptation time and the relative spatial frequencies of the test and adapting gratings. Their study showed that prolonging the adaptation time increased the effect but that it reached a plateau or even declined after about 1 min.

What happens after brief exposures of various duration? Gilinsky (1967) found that adapting exposures of $250 \mathrm{msec}$ and less had a facilitatory effect on visual acuity for identical orientations.

The effect of very brief durations of exposure to a striped pattern is still unsettled. Using exposure durations of 5,50 , and $500 \mathrm{msec}$, Houlihan and Sekuler (1968) found that the amount of masking of a vertical test bar by a grating at all of these rather brief adapting durations decreased as the grating was rotated over a range of $42 \mathrm{deg}$ from vertical. Their results are puzzling, for although the 5-msec condition produced the least amount of overall masking, as might be expected, 50 msec of adaptation actually produced slightly more masking than the longer 500-msec condition.

Some evidence suggests that with increasing exposure duration, the range of orientations to which orientation-selective units are responsive may diminish so that distortions of shape and inclination disappear (Andrews, 1967).

Mayo, Gilinsky, and Jochnowitz (1968) combined a forward visual masking method and absolute judgments of orientation of a grating in order to study the effects of adaptation on both sensitivity loss and tilt aftereffects. There were two independent variables: the orientation of the grating presented for initial prolonged inspection (the adapting grating) and the orientation of the second grating (the test grating) presented briefly immediately after the removal of the adapting grating. Using 5-sec adaptation to each of four different adapting orientations ( -15 , $+75,+30$, and $-60 \mathrm{deg}$ ), these investigators found that the forward masking of test gratings was significant up to \pm 10 deg of angular separation from the adapting grating. Masking was maximal either at 0 or 5 deg of separation, depending on the orientation of the adapting grating. The adapting orientation also caused a significant shift in the judged test orientation, shifting it away from the adapting orientation toward the vertical or the horizontal axis, whichever was nearest.

This change in the apparent orientation of lines was reported by Vernon (1934) and studied by Gibson (1937) and Gibson and Radner (1937).

Gibson suggested that the effect was similar to sensory adaptation of the sort exhibited by color, brightness, and temperature. He found that a grating tilted $10 \mathrm{deg}$ to the right of vertical caused an objectively vertical line seen through the grating, or immediately after its removal, to appear tilted $2 \mathrm{deg}$ to the left of vertical. When the grating was set at $20 \mathrm{deg}$, the contrast effect on a vertical line was much reduced, and at $45 \mathrm{deg}$ the effect disappeared. He found further that the tilt aftereffect would transfer from one eye to the other. He interpreted these results in terms of a partial and local neural adaptation process, in many respects like brightness and color adaptation, but at a higher (less peripheral) level of the visual system. His theory proposed that adaptation and negative contrast effects were modifications of the correspondence between a sensory series and a stimulus series involving sensory opposition. In the case of linear orientation, there are two such opposition series, centered about two independent norms or standards, the vertical and the horizontal. During a prolonged inspection, the correspondence between the sensory series and the stimulus series becomes altered in such a way as to reduce the discrepancy between the norm and the perception. This process has been called "normalization." It appears because of imbalance in opponent channels.

Köhler and Wallach (1944) disagreed with Gibson's interpretation and explained these and similar figural aftereffects as contour displacements involving the "satiation" of position-detecting mechanisms. Recent 


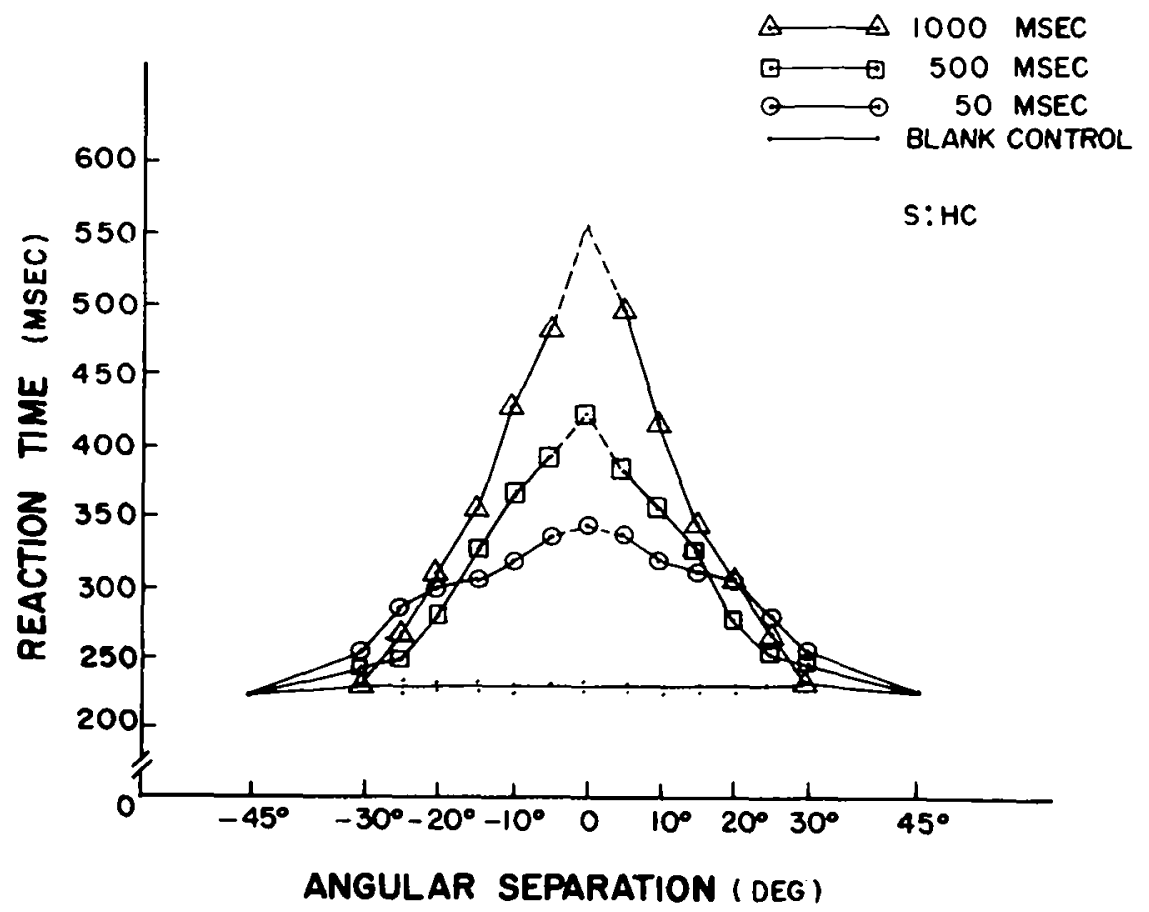

Fig. 1. Reaction time to change in orientation as a function of the angular separation between the adapting and the test atimuli, for S H.C. The dashed lines indicate failures to respond the masking effect.

evidence (Morant \& Harris, 1965; Templeton, Howard, \& Easting, 1965; Over, 1971) suggests that both normalization and satiation contribute to tilt aftereffects. Perhaps the current direction of research with its close ties to microelectrode studies of the receptive fields of single visual cells (Hubel \& Wiesel, 1965, 1968; Pettigrew, Nikara, \& Bishop, 1968) may provide the basis for resolving the long standing debate and a more adequate psychophysiological theory.

These studies leave open the question of the direction and extent of changes in visual acuity and tilt aftereffects on lines tilted in various orientations produced by a 45-deg diagonal-midway between the two primary anchoring meridians. We designed this experiment to determine if the 45-deg adapting stimulus would increase the latency of response to neighboring orientations and if it would produce diverging or converging shifts in judged orientation. The basic purpose of this study was to answer the following specific questions.

(1) How is orientational selectivity over the range from vertical to horizontal orientation affected by 50 $500-$ and $1,000-\mathrm{msec}$ periods of adaptation to a 45-deg adapting grating, as measured both by the time required to detect a change in the orientation of the grating and the amount of shift in perceived orientation?
(2) If, indeed, a 45-deg adapting stimulus does produce shifts in perceived orientation, what will be the direction and magnitude of such tilt

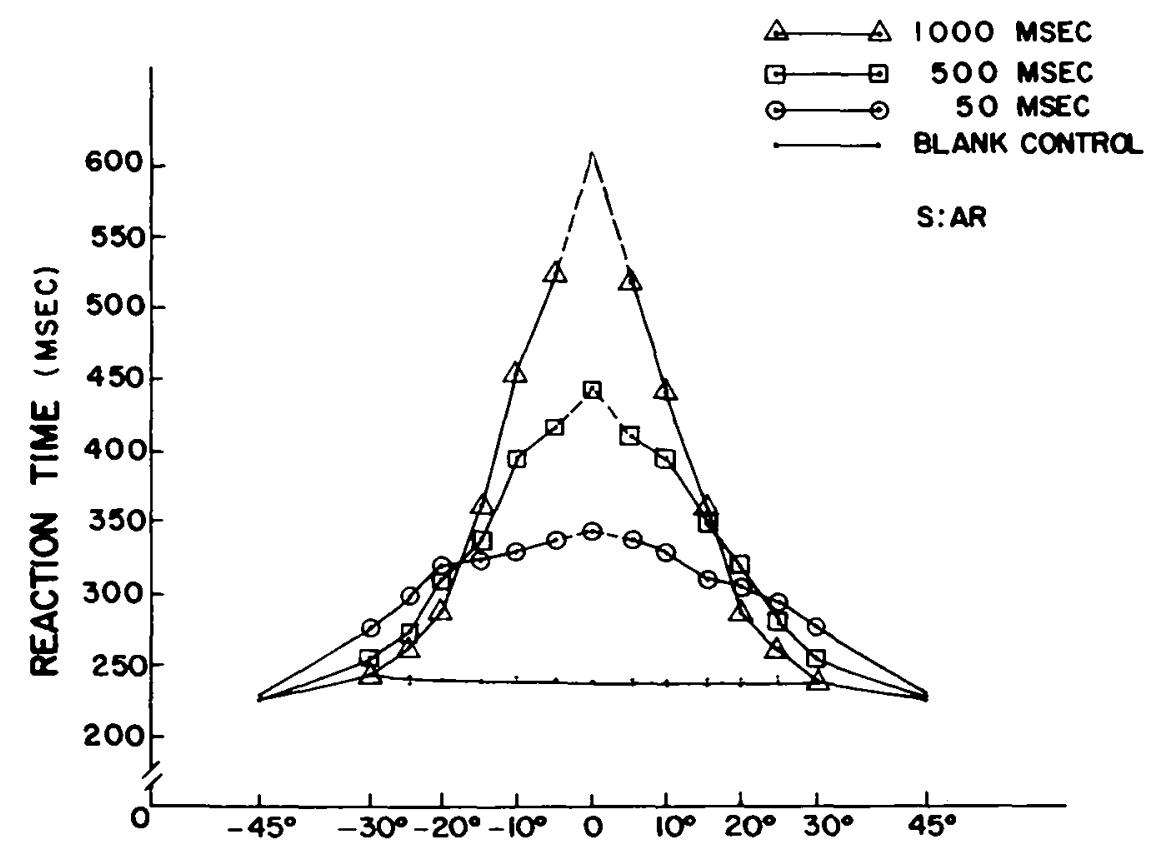

ANGULAR SEPARATION (DEG)

Fig. 2. Reaction time to change in orientation as a function of the angular separation between the adapting and the test stimuli, for S A.R. 
of 200-300 msec. The present study is believed to be the first to apply the method of reaction time to change to investigate orientational selectivity.

\section{METHOD}

Subjects

Two psychology graduate students, highly trained in the absolute discrimination of orientation of the test patterns, and well practiced in the RT task, served as Ss. Only the right eye of each $S$ was used. Both had normal uncorrected vision.

\section{Equipment and Materials}

Stimuli were 35-mm transparencies presented in a three-channel tachistoscope, Model GB, Scientific Prototype Co. Both adapting and test stimuli were constructed from Edmunds No. 2 patterns and consisted of parallel alternate black and clear lines $1 \mathrm{~mm}$ wide that subtended $8 \mathrm{~min}$ of arc at S's eye. Blanks consisted of clear plastic, mounted, as were all the stimuli, in Agfa slide frames and housed in slide trays that fed automatically into the tachistoscope.

A Monsanto timer, Model 100A, and response button were used to record RT. Luminances were about $30 \mathrm{~cd} / \mathrm{m}^{2}$ and $10 \mathrm{~cd} / \mathrm{m}^{2}$ for the adapting field and the test field, respectively. The stimulus display area was $4.5 \mathrm{deg}$ in diam and centered within an opaque black circular frame stop.

Table 1

Masking Data: Relative Frequency of "Blank" Responses to Test Stimuli 45 Deq \pm 10 Deg Test Stimuli (Degrees)

\begin{tabular}{|c|c|c|c|c|c|c|c|}
\hline & & & & Sti & li (Degr & & \\
\hline & & Blank & 35 & 40 & 45 & 50 & 55 \\
\hline Condition & $\mathbf{S}$ & & & Perce & Blanks & & \\
\hline 45 Deg Striate Ad & ion & & & & & & \\
\hline $\mathbf{5 0} \mathbf{M s e c}$ & $\begin{array}{l}\text { AR } \\
\text { HS }\end{array}$ & $\begin{array}{l}100 \\
100\end{array}$ & $\begin{array}{l}0 \\
0\end{array}$ & $\begin{array}{l}40 \\
30\end{array}$ & $\begin{array}{l}40 \\
40\end{array}$ & $\begin{array}{l}40 \\
20\end{array}$ & $\begin{array}{l}\mathbf{0} \\
\mathbf{0}\end{array}$ \\
\hline $500 \mathrm{Msec}$ & $\begin{array}{l}\text { AR } \\
\text { HS }\end{array}$ & $\begin{array}{l}100 \\
100\end{array}$ & $\begin{array}{l}0 \\
0\end{array}$ & $\begin{array}{l}40 \\
30\end{array}$ & $\begin{array}{l}60 \\
60\end{array}$ & $\begin{array}{l}30 \\
40\end{array}$ & $\begin{array}{l}0 \\
0\end{array}$ \\
\hline $1000 \mathrm{Msec}$ & $\begin{array}{l}\text { AR } \\
\text { HS }\end{array}$ & $\begin{array}{l}100 \\
100\end{array}$ & $\begin{array}{r}20 \\
0\end{array}$ & $\begin{array}{l}60 \\
50\end{array}$ & $\begin{array}{l}100 \\
100\end{array}$ & $\begin{array}{l}50 \\
60\end{array}$ & $\begin{array}{l}20 \\
20\end{array}$ \\
\hline Control (Nonstris & & & & & & & \\
\hline All Durations & $\begin{array}{l}\text { AR } \\
\text { HS }\end{array}$ & $\begin{array}{l}100 \\
100\end{array}$ & $\begin{array}{l}0 \\
0\end{array}$ & $\begin{array}{l}\mathbf{0} \\
\mathbf{0}\end{array}$ & $\begin{array}{l}0 \\
0\end{array}$ & $\begin{array}{l}0 \\
0\end{array}$ & $\begin{array}{l}\mathbf{0} \\
\mathbf{0}\end{array}$ \\
\hline
\end{tabular}

The adapting stimulus was a high-contrast grating fixed in orientation at $45 \mathrm{deg}$. For each duration tested, a blank adapting stimulus of equal average luminance was used to provide a baseline control. Interference produced by such a homogeneous field could be attributed merely to light adaptation. Any added interference produced by the grating would implicate the activity of contour-sensitive mechanisms.

There were 15 test orientations that were separated from the diagonal in 5-deg steps on both sides, plus the vertical and horizontal. A 45-deg test stimulus (identical with the adapting grating) and a blank "catch test" matched in average brightness, were

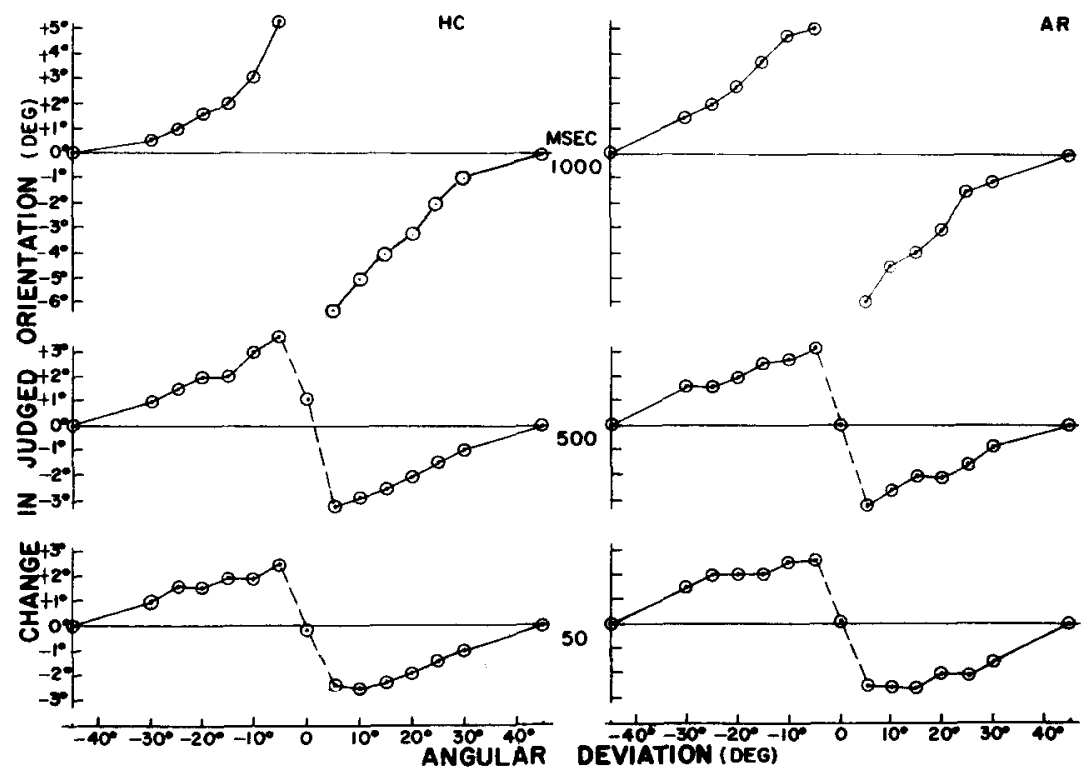

Fig. 3. Shifts in judged orientation for various degrees of separation and duration of adapting orientation. Note that positive changes in judgment are associated with negative (counterclockwise deviations of test stimuli), and negative changes in judgment are associated with positive (clockwise deviations of test stimuli). The dashed line indicates that the number of judgments was reduced because of masking. included as controls.

\section{Procedure}

The experiment tested three adapting durations: 50, 500, and $1,000 \mathrm{msec}$. The adapting stimulus, located in Field 2, was a 45-deg oriented grating, which was monocularly presented prior to each one of a series of 15 randomized test orientations located in Field 1, ranging in 5 -deg intervals from 15 to $75 \mathrm{deg}$ ( $\pm 30 \mathrm{deg}$ about the adapting stimulus), and including vertical, horizontal, and 0 -deg separation in which both the test and adapting orientations were identical, i.e., 45 deg. S was instructed to respond by pressing a button as soon as he detected a change in the orientation of the grating lines, but not to a blank or to an unchanged orientation. Thus, although the method resembled simple RT (a given trial had only one stimulus and one response), $\mathrm{S}$ had to detect a difference and we were measuring a discriminative response. (See Steinman, 1944; Woodworth \& Schlosberg, 1954, for discussion of the method.)

Each trial was preceded by a ready signal and a brightening of the field which provided a constant foreperiod of 2-sec interval prior to the onset of the test flash. Within this constant 2-sec interval, the adapting stimulus was presented for a period of 50,500 , or $1,000 \mathrm{msec}$ immediately before the test stimulus and simultaneous onset of the timer.

In order to prevent $S$ from inferring the moment of appearance of the stimulus from the onset of the foreperiod or the drop in luminance, the experiment included a blank catch test matched in average brightness to the test gratings. No false positive responses on the catch trials were allowed.

The Ss were thoroughly trained in both the RT task and in identification of the test orientations and, before each experimental session, were given 
Table 2

Mean Judgments of Orientation Following Three Durations of Adaptation to a 45-Deg Grating (Experimental) and to a Nonstriate Control

\begin{tabular}{|c|c|c|c|c|c|c|}
\hline \multirow[b]{3}{*}{$\begin{array}{c}\text { Test } \\
\text { Orientation } \\
\text { (Deg) }\end{array}$} & \multicolumn{6}{|c|}{$\begin{array}{l}\text { Mean Judged Orientation } \\
\text { Duration of Adaptation }\end{array}$} \\
\hline & \multicolumn{2}{|c|}{$50 \mathrm{Msec}$} & \multicolumn{2}{|c|}{$500 \mathrm{Msec}$} & \multicolumn{2}{|c|}{$1000 \mathrm{Msec}$} \\
\hline & $\begin{array}{l}\text { Experi- } \\
\text { mental } \\
\text { (Deg) }\end{array}$ & $\begin{array}{c}\text { Control } \\
\text { (Deg) }\end{array}$ & $\begin{array}{c}\text { Experi- } \\
\text { mental } \\
\text { (Deg) }\end{array}$ & $\begin{array}{c}\text { Control } \\
\text { (Deg) }\end{array}$ & $\begin{array}{c}\text { Experi- } \\
\text { mental } \\
\text { (Deg) }\end{array}$ & $\begin{array}{c}\text { Control } \\
\text { (Deg) }\end{array}$ \\
\hline $\begin{array}{r}0 \\
15 \\
20 \\
25 \\
30 \\
35 \\
40 \\
45 \\
50 \\
55 \\
60 \\
65 \\
70 \\
75 \\
90\end{array}$ & $\begin{array}{r}0.0 \\
20.5 \\
27.5 \\
31.0 \\
33.0 \\
42.0 \\
48.5 \\
49.2 \\
48.5 \\
52.5 \\
58.0 \\
60.5 \\
67.5 \\
72.0 \\
90.0\end{array}$ & $\begin{array}{r}0.0 \\
19.0 \\
25.5 \\
29.0 \\
31.0 \\
39.5 \\
46.0 \\
49.0 \\
51.0 \\
55.0 \\
60.0 \\
62.5 \\
69.0 \\
73.0 \\
90.0\end{array}$ & $\begin{array}{r}\text { S AR } \\
\text { 0.0 } \\
20.0 \\
27.5 \\
30.5 \\
33.5 \\
39.5 \\
46.5 \\
45.0 \\
47.9 \\
\mathbf{5 2 . 9} \\
\mathbf{5 7 . 0} \\
62.0 \\
68.0 \\
71.5 \\
\mathbf{9 0 . 0}\end{array}$ & $\begin{array}{r}0.0 \\
18.5 \\
26.0 \\
28.5 \\
31.0 \\
37.0 \\
43.5 \\
45.0 \\
51.0 \\
54.5 \\
54.0 \\
64.0 \\
69.5 \\
72.5 \\
90.0\end{array}$ & $\begin{array}{r}0.0 \\
21.5 \\
285 \\
31.0 \\
33.5 \\
38.1 \\
45.0 \\
- \\
46.0 \\
52.5 \\
56.0 \\
63.0 \\
67.0 \\
71.0 \\
90.0\end{array}$ & $\begin{array}{r}0.0 \\
20.0 \\
26.5 \\
28.5 \\
34.0 \\
33.5 \\
40.0 \\
46.5 \\
52.0 \\
57.0 \\
60.0 \\
66.0 \\
68.5 \\
72.0 \\
90.0\end{array}$ \\
\hline $\begin{array}{c}\text { Blank } \\
\text { "Catch" Test }\end{array}$ & Blank & Blank & Blank & Blank & Blank & Blank \\
\hline $\begin{array}{l}0 \\
15 \\
20 \\
25 \\
30 \\
35 \\
40 \\
45 \\
50 \\
55 \\
60 \\
65 \\
70 \\
75 \\
90\end{array}$ & $\begin{array}{r}0.0 \\
18.5 \\
23.0 \\
31.0 \\
38.5 \\
42.5 \\
50.0 \\
48.3 \\
51.1 \\
53.5 \\
60.0 \\
62.5 \\
66.5 \\
72.0 \\
90.0\end{array}$ & $\begin{array}{r}0.0 \\
17.5 \\
21.5 \\
29.5 \\
36.5 \\
40.5 \\
47.5 \\
48.5 \\
53.5 \\
56.0 \\
62.5 \\
64.5 \\
68.0 \\
73.0 \\
90.0\end{array}$ & $\begin{array}{r}\text { S HC } \\
\mathbf{0 . 0} \\
17.5 \\
24.0 \\
28.5 \\
34.5 \\
40.0 \\
42.9 \\
47.5 \\
48.3 \\
52.0 \\
58.0 \\
62.5 \\
67.5 \\
73.0 \\
90.0\end{array}$ & $\begin{array}{r}0.0 \\
16.5 \\
22.5 \\
26.5 \\
32.5 \\
37.0 \\
39.5 \\
46.5 \\
51.5 \\
55.0 \\
60.5 \\
64.5 \\
69.0 \\
74.0 \\
90.0\end{array}$ & $\begin{array}{r}0.0 \\
17.5 \\
24.0 \\
29.5 \\
35.5 \\
40.0 \\
47.0 \\
- \\
45.0 \\
50.0 \\
55.5 \\
63.0 \\
66.0 \\
73.0 \\
90.0\end{array}$ & $\begin{array}{r}0.0 \\
17.0 \\
23.0 \\
28.0 \\
33.5 \\
37.0 \\
42.5 \\
46.0 \\
51.5 \\
55.0 \\
\mathbf{5 9 . 5} \\
66.5 \\
68.0 \\
74.0 \\
90.0\end{array}$ \\
\hline $\begin{array}{c}\text { Blank } \\
\text { "Catch" Test }\end{array}$ & Blank & Blank & Blank & Blank & Blank & Blank \\
\hline
\end{tabular}

a brief warm-up. Each trial began and ended with the same pre- and postexposure field. A trial consisted of either a blank or a striate adapting stimulus for a period of 50,500 , or $1,000 \mathrm{msec}$, followed immediately by a test stimulus for a fixed duration of $350 \mathrm{msec}$. Two considerations determined this value. The test had to be presented at a duration well above threshold, yet brief enough to prevent the correction of errors in judgment. The $S$ responded by pressing a response button as soon as he detected a change in orientation of lines. Since $S$ was instructed not to respond to a perceived blank, blank catch trials were used to restrain $S$ from premature responding and as proof of valid discrimination of orientation.

Immediately after the $\mathrm{RT}$ response, $S$ gave an absolute judgment of the test stimulus value to which he reacted. His verbal response was one of the 15 possible test categories, or, if no pattern was detected, he responded "blank." He was instructed to try to use all categories. For each experimental duration, a blank adapting stimulus of equal average luminance and exposure duration served as a baseline control.

Each of two slide trays contained 32 randomly selected test stimuli ( $2 \times 16$ test stimuli). After each tray, $S$ was given a short rest break, while $\mathbf{E}$ varied the random order of the test stimuli in the used tray. In order to further minimize practice and fatigue effects, all conditions were counterbalanced such that each condition occurred equally often at each stage of practice and each condition preceded and followed all other conditions.

For a given adapting stimulus (45 deg or blank) and duration (50, 500 , and $1,000 \mathrm{msec}$ ), each test stimulus was presented 10 times in random order. A total of $N=960$ measures per $S$ were taken for each dependent variable, RT, and absolute judgment.

As soon as $\mathbf{S}$ identified a change in the orientation of the test grating, he pressed the response button shutting off the timer. This response latency in microseconds from the onset of the test stimulus gave the RT recorded for the given trial. The $S$ then reported his absolute judgment in degrees of the orientation of the test stimulus to which he had responded. In the control condition, $S$ responded to the onset of the test grating and did not respond to a blank catch test.

\section{RESULTS}

Reaction Time

The RT data are plotted as functions of the angle of separation between the test and the adapting gratings for each of the three adapting durations. Figures 1 and 2 show that results for the two Ss are similar. Peaks in the RT curves at 0 -deg separation show that $S$ sometimes responded to an apparent change in orientation even when the adapting and test gratings were identical.

Reactions to $45 \mathrm{deg}$ were forbidden, but Table 1 shows that they did sometimes occur following the briefer adapting durations. In those cases, $\mathbf{S}$ was responding to a perceived change in orientation because the judgments never fell in the 45-deg category but were shifted to one side or the other of $45 \mathrm{deg}$. Following the longest adapting duration $(1,000 \mathrm{msec})$, there were no responses to $45 \mathrm{deg}$ other than "blank." Since blank responses indicate masking (loss of sensitivity) and adjacent test stimuli (40-55 deg) were called "blank" with increasing frequency as the duration of adaption was increased, we can infer that masking did occur as a function of duration to those orientations 5-10 deg removed from the 45-deg diagonal. A comparison of the frequency of blank responses following striate adaptation with the frequency of blank responses to the same test stimuli following blank adaptation is evidence of selective adaptation (see Table 1 ).

The slopes near the peaks steepen and the curves shift upward as the duration of the adapting grating increases. All of the curves are reasonably symmetrical, which indicates that the direction of angular rotation, clockwise or counterclockwise from the diagonal, is not an important variable. The reactions to the test stimuli following the three different durations of nonstriate light were nearly identical. These points were so overlapping that they were not plotted separately for the three duration conditions. The baseline, drawn through the RT data following the blank control conditions, is horizontal and shows no effect of duration or test orientation over most of the range. Only at the 
extremes, the reactions to vertical and horizontal were slightly but significantly $(p<.01)$ faster than to oblique orientations. In sharp contrast, the reactions to the test stimuli within 15-20 deg on either side of the 45-deg adapting grating are strikingly affected by the exposure to striate light produced by the adapting grating.

An analysis of variance based on a three-factor repeated-measurements design performed on the RT data (the differences between striate and control RTs) showed that both angular separation and adapting duration had significant effects beyond the .01 level. The $\mathbf{S}$ factor was significant at the .05 level, but the interactions were not significant. Thus, Ss did not differ in their pattern of responding.

It is of interest to note that the curves for separate durations cross at separations of about $15-20 \mathrm{deg}$ away from the adapting gratings on both sides. The symmetry of these crossover effects and their occurrence in both Ss suggests that the duration variable exerts more than one systematic effect. Depending on the orientation of the test relative to the adapting pattern, the effect of increasing duration is to increase $R T$, as shown clearly here, between $\pm 15 \mathrm{deg}$ deviation from the adapting diagonal, or the effect may be to decrease RT at larger separations.

\section{Tilt Aftereffects}

Table 2 and Fig. 3 present the data for both Ss separately following the three conditions of adaptation duration. The dependent variable of interest is the mean shift in absolute judgment following the 45-deg adapting stimulus minus the control judgments of these test orientations.

A three-factor repeatedmeasurements design was again used for the analysis of variance of the shift effect, the criterion being the change in mean responses to test stimuli following three durations of adaptation. Angular separation and adapting duration were again both significant beyond the .01 level. The interaction between these factors was also significant at the .01 level. Again, the patterns of responding were not significantly different between Ss.

The most striking result is that responses for both $\mathrm{S}_{s}$ to all conditions of angular separation and adapting duration systematically shift in the direction of the $45-\mathrm{deg}$ adapting orientation. This convergence of judgments is stronger the closer the test orientation is to the $45-\mathrm{deg}$ adapting stimulus. Conversely, shift is weak or absent at extreme separations.

Figure 3 shows clearly that the maximal shift in judged orientation is most pronounced (5-6 deg) at the 1,000-msec adaptation condition and least pronounced (2.5 deg) at the 50-msec condition. Note that the vertical and horizontal gratings were always judged correctly regardless of the condition of adaptation. Since this convergence of shifted judgments is most pronounced following 1,000 msec of adaptation, the strength of the effect would seem to be related to increasing duration of the adapting stimulus.

\section{DISCUSSION}

Previous studies have clearly demonstrated that adapting duration and angular separation are important variables for discriminating orientations in a masking situation. The results of this study using a $R T$ method verify and extend these findings. Response latency was shown to be an inverse function of angular separation between test and adapting contours, i.e., the greater the change in orientation, the shorter the RT. RT to change in orientations of lines is, therefore, a direct and effective measure of orientational discriminability.

Increasing the duration of the adapting stimulus increased the magnitude of the effect on RT and the spread of effect to remote orientations. Unlike the results of Houlihan and Sekuler (1968), the curves relating adapting duration and angular separation within the \pm 15 - to 20-deg range reveal that the RT curves steepen monotonically with increasing durations of the adaptation grating.

The shifts in absolute judgments of test orientations have interesting theoretical implications. Previous results suggest that both the Gibson and the Kühler type processes may be operating concurrently (see Howard \& Templeton, 1966). In support of Gibson's normalization hypothesis, it is noteworthy that the responses to vertical and horizontal test stimuli were always correct. The evidence clearly shows that Ss are more accurate (see review by Taylor, 1963) and faster (Attneave \& Olson, 1967) in responding to vertical and horizontal stimuli than to oblique orientations.

Yet, the tilt aftereffects of the 45-deg inspection lines of the present study yielded results unlike those obtained by Gibson and Radner (1937), Morant and Harris (1965), Muir and Over (1970), and Templeton, Howard, and Easting (1965), and would not be predicted either by Gibson (1937) or Köhler and Wallach (1944) or by an algebraic summation of the two theories. Shifted judgments were not in the direction of the nearest main axis, vertical or horizontal, nor did they cancel out, either of which outcomes Gibson's normalization theory would predict, nor did they diverge away from the adapting stimulus, as Köhler's satiation theory would predict. Rather, judgments of test orientations converged upon the 45 -deg adapting stimulus. A possible explanation might be that the 45-deg diagonal orientation has "natural" anchoring properties.

Any thorough explanation of anchoring must account for underlying neural mechanisms which selectively channel judgments toward various anchoring stimuli. Bouma and Andriessen (1970) suggest that neural cells responsive to vertical and horizontal orientations are, perhaps, more numerous or more active than other orientation detectors. Perhaps increasing the duration of anchoring stimuli enhances convergence by exciting relatively greater frequency of discharge or by recruitment of selectively responsive units.

The experiment demonstrated the usefulness of the method of RT to change for research of this kind. Compared to other psychophysical methods, RT to change has several advantages. First, it is like the typical simple RT because there is but one stimulus for the reaction and one response. Yet the response involves a discrimination between two values of the stimulus and, thus, although shorter and less variable than the disjunctive RT (Steinman \& Veniar, 1944; Attneave \& Olson, 1967), retains the essential feature of measuring a discrimination. Secondly, the method offers a prompt and reliable measure of the difficulty of discrimination over a wider range than the threshold sensitivity measures because RT continues to decrease beyond the $100 \%$ point of correct responding. It thus provides a measure of the discriminability of large differences well above threshold and supplements methods of subjective judgment. These results, using RT to clearly visible changes in orientation, show rapid adaptation effects and rapid recovery. The speed of recovery is related to the duration of exposure to the adapting stimulus.

The R'T data confirm and extend the inference of masking studies that orientation-specific detectors exist in the human visual system (Campbell \& Kulikowski, 1966; Gilinsky, 1967 , 1968; Mayo et al, 1968; Gilinsky \& Doherty, 1969; Houlihan \& Sekuler, 1968; Weisstein, 1969).

Additional support for this conclusion was obtained from an analysis of the tilt aftereffects. The convergence of judgments toward the adapting $45-\mathrm{deg}$ diagonal shows the importance of this oblique orientation as a secondary or derived anchor. Unlike the vertical and horizontal 
coordinates, the diagonal is not a primary anchor because RT does not show a marked dip when, under the blank control condition, the test stimulus is oriented at $45 \mathrm{deg}$, as it does when the orientation is vertical or horizontal. The observed width of tuning (about $15 \mathrm{deg}$ ) is in relatively good agreement with previous findings for oblique orientational channels (see Campbell \& Ku!ikowski, 1966; Gilinsky \& Mayo, 1971).

The method of RT to change and the method of absolute judgment were found to provide converging quantitative information about orientation selectivity in the visual system of man. Both methods agree in showing similar effects of orientational adaptation as functions of duration and angular separation of adapting contours. RT increased markedly, and shifts in judgment became more pronounced as the duration, even at the relatively brief exposures, was increased from 50 to $1,000 \mathrm{msec}$ and as the test orientation was brought closer to the adapting orientation.

Some special properties of the vertical and the horizontal coordinates were noted. Judgments of the vertical and the horizontal gratings were always correct, both after and before adaptation. RTs were consistently shorter for the two primary coordinates also. The greater speed and accuracy of the response to the vertical and horizontal coordinates in the control condition is consistent with other evidence and supports a structural interpretation of orientational selectivity in man (Campbell, Kulikowski, \& Levinson, 1966; Campbell \& Maffei, 1970; Maffei \& Campbell, 1970; Pettigrew, Nikara, \& Bishop, 1968).

\section{REFERENCES}

ANDREWS, D. P. Perception of contour orientation in the central fovea, Part 1: Short lines. Vision Research, 1967, 7, 975-997.

A TTNEAVE, F., \& OLSON, R. K. Discriminability of stimuli varying in physical and retinal orientation. Journal of Experimental Psychology, 1967, 74, 149.157

BLAKEMORE, C., \& CAMPBELL, F. W. On the existence of neurones in the human visual system selectively sensitive to the orientation and size of retinal images. Journal of Physiology, 1969, 203, 237-260.

BOUMA, H., \& ANDRIESSEN, J. J. Induced changes in the perceived orientation of line segments. Vision Research, 1970, 10, 333-349.

CAMPBELL F, W \& KULIKOWSKI, J, J Orientational selectivity of the human visual system. Journal of Physiology, $1966,187,437-445$.

CAMPBELL, F. W., KULIKOWSKI, J, J, \& LEVINSON, J. The effect of orientation on the visual resolution of gratings. Journal of Physiology, 1966, 187, 427-436.

CAMPBELL, F. W., \& MAFFEI, L. Electrophysiological evidence for the existence of orientation and size detectors in the human visual system. Journai of Physiology, 1970, 207 , 635-652.

COLTHEART, $M$. Visual feature-analyzers and aftereffects of tilt and curvature. Psychological Review, 1971, 78, 114-121. GIBSON, J. J. Adaptation, after-effect and contrast in the perception of tilted lines. II. Simultaneous contrast and areal restriction of the after-effect. Journal of Experimental Psychology, 1930, 20, Experim

GIBSON, J. J.. \& RADNER, M. Adaptation, after-effect and contrast in the perception of tilted lines. I. Quantitative studies. Journal of Experimental Psychology, $1937,20,453-467$.

G ILINSKY, A. S. M a sking of contour-detectors in the human visual system. Psychonomic Science, 1967, 8, 395-396.

GILINSKY, A. S. Orientation-specific effects of patterns of adapting light on visual acuity. Journal of the Optical Society of America, 1968, 58, 13-18.

GILINSKY, A. S., \& DOHERTY, R. Interocular transfer of orientational effects. Science, $1969,164,454-455$.

GILINSKY, A. S., \& MAYO, T. Exeitatory and inhibitory effects of orientational adaptation. Journal of the Optical Society of America, 1971, 61, 689-690.

HOWARD, I. P.. \& TEMPLETÓN, W. B. Human spatial orientation. New York: Wiley, 1966.

HOULIHAN, K., SEKULER, $R$ W Contour interactions in visual masking. Journal of Experimental Psychology, 1968, 77, 281-285.

HUBEL, D. H., \& WIESEL, T. N. Receptive fields and functional architecture in two nonstriate visual areas (18 and 19) of the cat. Journal of Neurophysiology, 1965, 28, 229-289.

HUBEL, D. H., \& WIESEL, T. N. Receptive fields and functional architecture of monkey striate cortex. Journal of Physiology, 1968, 195, 215-243.

KÖHLER I, \& WALLACH, H Figural after-effects: An investigation of visual processes. Proceedings of the American Philosophical Society, 1944, 88, 269-357.

MAFFEI, L., \& CAMPBELL, F. W Neurophysiological localization of the vertical and horizontal coordinates in man. Science, 1970, 167, 386-387.

MAYO, T. H., GILINSKY. A. S., \& JOCHNOWITZ, A. Visual masking and tilt aftereffects as a function of tilt and angular separation between test and adaptation line patterns. Proceedings of the 76th Annual Convention of the American Psychological Association. 1968, 3, 97-98.

MORANT, R. B., \& HARRIS, J. R. Two different aftereffects of exposure to visual tilts. American Journal of Psychology, 1965, 78, 218-226.

MUIR, D., \& OVER, R. Tilt aftereffects in central and peripheral vision. Journal of Experimental Psychology, 1970. 85 . 165-170.

OVER, R. Comparison of normalization theory and neural enhancement explanation of negative aftereffects Psychological Bulletin, 1971, 75 . 225-243.

PETTIGREW, J. D., NIKARA, T., \& BISH OP, P. O. Responses to moving slits by single units in cat's striate cortex. Experimental Brain Research, 1968, 6, 373-390.

STEINMAN, A. Reaction time to change in comparison with other psychophysical methods. Archives of Psychology, 1944. No. 292 .

STEINMAN, A., \& VENIAR, S. Simple reaction time to change as a substitute for the disjunctive reaction. Journal of Experimental Psychology, 1944, 34, $152-158$.

TAYLOR, M. M. Visual discrimination and orientation. Journal of the Optical Society of America, 1963, 53, 763-765.

TEMPLETON, W. B.. HOWARD, I. P.. \& EASTING, G. Satiation and the tilt aftereffect. American Joumal of Psychology, 1965, 78, 656-659.

$\checkmark E R N O N, M$. D. The perception of inclined lines. British Joumal of Psychology, $1934,25,186-196$.

WOLL, S., ERIKSEN, C, W, HAKE, H W. A forced-choice study of edge detectors in the human visual system. Perception \& sychophysies, 1970,9, 247-252.

WEISSTEIN, $N$. What the frog's eye tells the human brain: Single cell analyzers in the human visual system. Psychological Bulletin, 1969, 72, 157-176.

WOODWORTH, R. S., \& SCHLOSBERG, H. Experimental psychology. New York: Holt, 1954

(Accepted for publication July 5, 1971.) 